\title{
Conflitos e Tensões no Acesso dos Recursos Terra-Água
}

\author{
Conflicts and Tensions in Accessing Land-Water Resources
}

Conflictos y Tensiones en el Acceso a los Recursos Tierra-Agua

\author{
Abraão Levi dos Santos Mascarenhas ${ }^{1}$ \\ https://orcid.org/0000-0003-0546-8836 \\ Maria Rita Vidal ${ }^{2}$ \\ (iD) https://orcid.org/0000-0002-3392-3624
}

RESUMO: Disputas por acesso aos recursos naturais sempre vêm seguidas por tensões e conflitos entre os agentes envolvidos. Na Região Amazônica esta tônica é acompanhada por atos violentos, muitas das vezes utilizando a força policial legitimada pelo próprio Estado. O fato é que as políticas de dotação de infraestruturas (empreendimentos de larga escala) sempre consideram as populações originárias como contingências territoriais que precisam ser equacionadas pelos governos. A partir dos dados coletados pela Comissão Pastoral da Terra para o ano de 2018, associados à cartografia temática, buscou-se especializar as tipologias dos conflitos ambientais e socioambientais e entender a relação destas com o acesso aos recursos terra-água em duas regiões hidrográficas (Itacaiúnas e Tocantins) no Estado do Pará, levando em conta os conceitos/entendimentos dos tipos de conflitos para os povos indígenas, ribeirinhos, pescadores e assentados da reforma agrária. $O$ uso da cartografia permitiu espacializar e analisar três áreas que concentram tais conflitos, aqui denominados de células de conflitos, estando concentradas nos municípios de Tucuruí, Marabá/Bom Jesus do Tocantins, além de Parauapebas/Canaã dos Carajás. Estes conflitos são produtos das relações sociais/ambientais/territoriais entre empreendimentos de mineração, pecuárias e projeto de implementação de hidrovia, contrapondo-se aos modos de vida tradicionais que buscam defender seus espaços.

PALAVRAS-CHAVE: Recursos. Conflitos. Água. Bacia hidrográfica.

ABSTRACT: Disputes over access to natural resources have always been followed by tensions and conflicts between the agents involved. In the Amazon Region, this is accompanied by violent acts, often using the police force legitimized by the State. It is a fact that infrastructural endowment policies (large-scale enterprises) always consider native populations as territorial contingencies that must be addressed by governments. From the data collected by the Pastoral Land Commission for 2018, associated with thematic cartography, it was sought to specialize the typologies of environmental and

\footnotetext{
${ }^{1}$ Doutor em Geografia pela USP. Professor na Universidade Federal do Sul e Sudeste do Pará. E-mail: abraaolevi@unifesspa.edu.br.

${ }^{2}$ Doutora em Geografia pela UFC. Professora na Universidade Federal do Sul e Sudeste do Pará. E-mail: ritavidal@unifesspa.edu.br.
} 
socio-environmental conflicts and understand their relationship with access to land-water resources in two hydrographic regions (Itacaiunas and Tocantins) in the State of Para, considering the concepts of the types of conflicts for indigenous peoples, riverside dwellers, fishermen, and agrarian reform settlers. The use of cartography allowed to specialize and analyze three areas that concentrate such conflicts, here called conflict cells, being concentrated in the municipalities of Tucurui, Maraba/Bom Jesus do Tocantins, and Parauapebas/Canaa dos Carajas. These conflicts are the product of social/environmental/territorial relations between mining and livestock enterprises and a waterway implementation project, in contrast to traditional ways of life that seek to defend their spaces.

KEYWORDS: Resources. Conflicts. Water. Hydrographic basin.

RESUMEN: Las disputas por el acceso a los recursos naturales siempre son seguidas por tensiones y conflictos entre los actores implicados. En la Región Amazónica esta temática se acompaña de actos violentos, las veces utilizando la fuerza policial legitimada por el propio estado. El hecho es que la dotación de las políticas de infraestructuras (grandes emprendimientos) siempre tienen en cuenta las poblaciones como contingencias territoriales que deben ser abordadas por los gobiernos. A partir de los datos recopilados por la Comisión Pastoral de Tierras para el ano de 2018, asociados a la cartografía temática, buscamos la espacialización de las tipologías del conflictos ambientales y socioambientales, comprendiendo cuál es su relación con el acceso a los recursos tierra-agua en dos regiones hidrográficas (Itacaiúnas y Tocantins) en el Estado de Pará, teniendo en cuenta los conceptos/comprensión de los tipos de conflictos para pueblos indígenas, ribereños, pescadores y asentados de la reforma agraria. El uso de la cartografía permitió espaciar y analizar tres áreas que concentran tales conflictos, aquí llamadas células de conflicto, concentrándose en los municipios de Tucuruí, Marabá/Bom Jesus do Tocantins, además de Parauapebas/Canaã dos Carajás. Estos conflictos son producto de relaciones sociales/ambientales/territoriales entre emprendimientos mineros, ganaderos y proyectos mineros en la vía fluvial, en contraste con las formas de vida tradicionales que buscan defender sus espacios.

PALABRAS CLAVE: Recursos. Conflictos. Agua. Cuenca hidrográfica.

\section{INTRODUÇÃO}

Os empreendimentos de larga escala implementados pelas políticas de Estado (hidrelétricas, hidrovias, portos etc.) têm suscitado um cenário tendencial de conflitos socioambientais no tocante ao acesso aos recursos naturais terra-água. Estes empreendimentos direcionam as questões dos conflitos ambientais e socioambientais, pontuados por lutas por acesso aos recursos hídricos e sua melhor qualidade. No Brasil, como impacto direto na vida das comunidades, os usos múltiplos e as políticas de transportes intermodais (ferrovia, hidrovia, porto) que vêm sendo pensadas para a bacia hidrográfica do Tocantins-Araguaia, tomando como exemplo a reestruturação das bacias Itacaiúnas/Tocantins, seguem esta mesma lógica.

O extremo leste da Amazônia paraense tem concentrado atividades como o extrativismo mineral e vegetal, pecuária intensiva e extensiva e produção de energia, que geram demandas, novas políticas de integração nacional, construindo vetores de expansão, os quais tratamos como eixos de propagação do agronegócio da soja com toda a sua cadeia 
produtiva. Nesta dinâmica é possível falar também do eixo de propagação das atividades graneleiras e seus insumos de produção.

No contexto da intensificação do uso dos recursos naturais que demandam terra-água, a porção do território paraense na confluência dos Rios Itacaiúnas e Tocantins vem passando por desestruturação do ambiente natural, trazendo modificações significativas na dinâmica espacial e atributos ambientais. As formas de uso do solo interferem de forma significativa nos ciclos da água, na vazão e na irregularidade da distribuição das chuvas que devem ser analisadas a partir do clima regional, bem como seus sistemas sinóticos perturbadores. Pensa-se que a dinâmica nas formas de usar os recursos hídricos em bacia hidrográfica segue um padrão seletivo, em conformidade com os interesses dos grupos sociais, o que potencializa os conflitos socioambientais.

Duas premissas irão guiar as questões dos conflitos nas bacias investigadas: a) as lutas por acesso aos recursos hídricos; e b) os tensionamentos para manter a qualidade dos recursos, para ausência de poluição nos mananciais. Assim, os conflitos que tencionam as relações sociais carecem ser melhor analisados, apontando metodologias mais adequadas para a gestão e justiça ambiental. Para tanto, objetiva-se identificar e espacializar as tipologias dos conflitos ambientais e socioambientais na porção da confluência da bacia do Itacaiúnas e Tocantins, para em seguida apontar proposições de gestão destes conflitos.

A escolha da bacia hidrográfica é tomada como uma extensão mensurável e como uma realidade objetiva, na qual os fenômenos sociais são dinamizados por conta da riqueza hídrica apresentada e pelo uso predatório (uso-abuso) das águas que drenam esta unidade de planejamento. Todos estes tensionamentos e conflitividades têm na justiça ambiental uma convergência no sentido de atenuá-los.

\section{FUNDAMENTAÇÃO TEÓRICA}

As populações originárias (camponeses desapropriados que perderam suas terras e pescadores artesanais que têm nos recursos aquáticos a base material de subsistência) lutam para preservar as funções e serviços ecossistêmicos das suas terras através dos movimentos sociais. Estes movimentos sociais estão focados em estabelecer justiça ambiental (gerados por conflitos ambientais e socioambientais) que leve em conta seu reconhecimento enquanto seres humanos, que tem direito em acessar a água para continuarem a se desenvolver.

A justiça ambiental, a partir da dimensão dos movimentos antimineração da América Latina, para Urkidi e Walter (2011), é definida como luta em prol da garantia de direitos a um ambiente saudável, no sentido de alocar bens, recursos, riquezas e qualidade de vida para 
todas as populações. A justiça ambiental é caracterizada por Martínez-Alier (2007, p. 230) como:

[...] o movimento organizado contra o "racismo ambiental", isto é, a distribuição desproporcional de resíduos tóxicos junto às comunidades latinas ou afro-americanas em situações urbano-industriais, no interior dos Estados Unidos, também se aplica às áreas de reservas dos povos indígenas dos Estados Unidos, particularmente no contexto dos resíduos nucleares e da mineração do urânio.

Tomamos emprestada a categoria de análise "conflitos ambientais" das Ciências Sociais a fim de revelar o pulso social, bastante evidente, ocorrido nos trechos dos rios Itacaiúnas e Tocantins. Tal categoria (conflitos ambientais), conforme Acselrad (2004, p. 22), se define como:

[...] envolvendo grupos sociais com modos diferenciados de apropriação, uso e significação do território, tendo origem quando pelo menos um dos grupos tem a continuidade das formas sociais de apropriação do meio que desenvolvem ameaçada por impactos indesejáveis - transmitidos pelo solo, água, ar ou sistemas vivos - decorrentes do exercício das práticas de outros grupos. O conflito pode derivar da disputa por apropriação de uma mesma base de recursos ou de bases distintas, mas interconectadas por interações ecossistêmicas mediadas pela atmosfera, pelo solo, pelas águas etc.

As diferentes maneiras empregadas por atores sociais no sentido de se apropriarem dos recursos naturais, incluindo a água, geram tensões conflitivas - as quais caracterizamse por relações balizadas por assimetrias nas relações de poder dentro de disputas por domínios espaciais, pois a percepção de dano, riqueza e bem-estar tem diferentes níveis de apreensão, que passam pelas visões econômicas, religiosas, culturais e até mesmo cosmogênicas. É o que Acselrad (2004) vai tratar como concepção material socializada e adoção de significados. Adotaremos a questão das tensões como fenômeno social de assimetria nas relações de poder, capazes de gerar violência e que em momentos de acirramentos leva a conflitos.

Assim, podemos chamar a atenção para a forma que se conduz determinado processo de desenvolvimento, que traz em seu bojo múltiplos interesses. Estas tensões são geradoras de conflitos pela forma como os grupos sociais se articulam, como nos afirma Vianna (1997, p. 25):

Os conflitos entre interesses privados e interesses coletivos ou públicos relacionados aos problemas ambientais são conflitos sociais porque envolvem a natureza e a sociedade, mas acontecem a partir de um tipo determinado de organização da sociedade. 
Os arranjos territoriais que configuram as células de conflitos são formatados pelas relações sociais e tensões políticas com o objetivo de garantir a permanência dos usos dos recursos naturais. O uso dos recursos naturais tem originado conflitos nas formas de apropriação pelos mais diversos atores sociais, que encontram na natureza uma maneira de se reproduzir com eficiência e ganhos econômicos. O conflito é inerente ao ser humano quando estão em jogo os recursos terra-água. E é este sentido de contradição de interesses individuais ou coletivos que possibilita traçar a origem e os motivos das questões conflituosas dos atores sociais. A natureza social, econômica e ambiental de certos grupos humanos leva às características específicas geradoras de conflitos.

A percepção de conflitualidade é o ponto de partida para a busca de justiça ambiental, ou mesmo de equacionar os conflitos. A este respeito, Acselrad (2002, p. 52) nos ajuda a compreender que justiça ambiental é a "[...] articulação entre injustiças sociais e degradação ambiental em conjunto com lutas sociais, territoriais e direitos civis realizadas pelos movimentos que almejavam alcançar a justiça ambiental."

No ano de 1997, o Instituto Brasileiro de Análises Sociais e Econômicas (IBASE) pontuava que momentos de tensões entre interesses coletivos e interesses privados aconteciam devido ao uso/apropriação de espaços e recursos:

Em geral, eles (os conflitos [...]) se dão pelo uso ou apropriação de espaços e recursos coletivos por agentes econômicos particulares, pondo em jogo interesses que disputam o controle dos recursos naturais e o uso do meio ambiente comum, sejam esses conflitos implícitos ou explícitos (VIANNA, 1997, p. 28).

Para entender como estes conflitos vão sendo delineados, é mister pontuar que na acepção clássica do conceito eles estão associados à confrontação de humanos acerca da natureza (PALACIO, 2002). Ainda segundo o autor, os conflitos são vetores de mudanças sociais e caminho para compatibilizar interesses sociais.

Dessa maneira, as lutas por acesso aos recursos hídricos buscam diminuir as fontes de poluição dos recursos que se apresentam como vetores de poluição nos mananciais (agrotóxicos ou resíduos da mineração).

O Estado representado por empresas e os demais atores sociais deixam marcas profundas sobre o arranjo territorial, impondo-se como modelo de desenvolvimento desigual, injustamente social e ecologicamente degradante às populações originárias, que lutam para preservar as funções/serviços ecossistêmicos das suas terras. Os camponeses desapropriados que perderam suas terras reafirmam (assim) que as comunidades haliêuticas têm nos recursos aquáticos seu insumo como elemento de existência.

O processo de (de)predação do atual sistema econômico na Amazônia tem deixado marcas profundas no tecido social. E de outra maneira se caracteriza, primeiramente, pelo 
não reconhecimento das populações originárias e dos agricultores, os quais têm uma relação não-mercantilista com os recursos naturais.

A sobrevivência de parcela da população tem se tornado vulnerável aos problemas ambientais ocasionados pelos projetos de infraestruturas de larga escala, que têm sua origem em acordos internacionais entre países proponentes. Estes vetores políticos de ordenamento territorial são a origem de todos os movimentos de mobilização por justiça ambiental, retratada por Leroy $(2011$, p. 2) da seguinte maneira:

Seja na construção de barragens hidroelétricas, na carcinicultura, na hotelaria, na exploração madeireira, na mineração e na metalurgia, todos os empreendedores comportam-se como predadores dos ecossistemas e das populações locais e donos do território.

O movimento que contesta os resíduos gerados por atividades industriais tem um caráter mais amplo em relação aos movimentos ambientais da proteção da vida silvestre; seu foco é a luta social pela qualidade do ambiente e garantia dos serviços ecossistêmicos.

Sabatini (1997) pontua a possibilidade de pensar os conceitos de conflitos ambientais socioambientais, os quais têm diferenças e similaridades, para combater as injustiças ambientais, assim afirmando:

Conflitos ambientais: são conflitos em torno da distribuição das denominadas externalidades ou efeitos externos derivados das mudanças nos usos do solo, ou seja, as novas atividades que se desenvolvem em um só lugar [...] Conflitos socioambientais: são disputas causadas pelo acesso e controle dos recursos do meio ambiente, especialmente da terra, porém também das águas, os minerais ou outros (SABATINI, 1997, p. 52, grifo e tradução nossa).

As diferenças existem e precisam ser ajustadas à nossa realidade. Algo comum nas duas acepções é o fato que há um processo de distribuição de externalidade/efeito distributivo de forma espacialmente desigual e que aumenta (ainda mais) as tensões sociais, ou seja, processo de violências como ameaças, expulsões e morte.

Para Zhouri e Laschefski (2010), existem três modalidades de conflitos que se configuram como questões ambientais - dessa forma podem aparecer conflitos distributivos (associados a desigualdades sociais no acesso aos recursos naturais), espaciais (conflitos que expandem seus limites no espaço de várias parcelas de grupos sociais), e territoriais (que têm como origem relações capitalistas com base no território).

A ideia de conflito guarda a contradição social que na acepção de Palacio (2002) demonstra que no conceito original de conflito está o contraditório humano, o qual torna-se propulsor de mudanças nas relações sociais, estando imbricadas negociações, disputas, lutas e enfrentamentos. Aqui podemos correlacionar com a proposta de Sabatini (1997) que 
faz uma distinção entre conflitos socioambientais e conflitos ambientais, dos quais a linha tênue é a relação entre mudanças na oferta dos serviços ambientais e assimetria nas relações de poder.

Sob a perspectiva da força e da desigualdade que estão os limites dos conflitos, PortoGonçalves (2018) nos chama a refletir que os conflitos são a materialidade das contradições sociais, das quais se vive e se sente tensões territoriais e fazem com que se amplie o conhecimento sobre os problemas da sociedade.

Os conflitos no Brasil foram analisados por Girardi (2019), realizando profunda discussão sobre as políticas agrárias de assentamentos rurais e a permanência dos conflitos e da violência no campo. Já Mello-Théry (2011) imprime um olhar sobre a gestão territorial e ambiental em terras públicas que sempre estão rodeadas de conflitos. Nesta mesma linha de argumentação, Coelho, Cunha e Monteiro (2009) relatam que a implementação de unidades de conservação está envolvida em conflitos territoriais de gênese diversa.

A região amazônica ainda é pensada como fronteira agrícola, seus ricos mananciais devem ser conservados para a manutenção dos serviços ecossistêmicos, para o bem da floresta e das populações que nela vivem. Esta rica geodiversidade e a sociobiodiversidade precisam ser potencializadas enquanto recursos econômicos articulados com 0 desenvolvimento regional, visando a proteção e manutenção dos serviços ecossistêmicos da bacia hidrográfica.

A bacia hidrográfica é um sistema que pode ser compreendido e descrito no espaço geográfico através das formas produzidas, resultantes dos usos dos que ordenam o território - ressalta-se que Brunet (2001) afirma que os indivíduos não impõem as formas no espaço aleatoriamente, existem regras e leis compartilhadas, cabendo o uso das táticas territoriais para a organização do espaço, sendo resultante da prática social. As políticas que visam produzir um espaço funcional para as atividades do agronegócio estão intimamente ligadas aos eixos de integração e desenvolvimento de infraestruturas; políticas que não levam em consideração os territórios de populações originárias e muito menos estão dispostas a realizar negociações ou mesmo concessões de dividendos.

Problemática de conflitos e tensões ambientais e socioambientais encravada entre as áreas de produção de minério e energia, as mudanças e/ou permanências no uso e cobertura do solo tendem a ser frequentes caso não se tenha mudanças na metodologia de negociação e de governança das políticas de desenvolvimento.

Tendo como aporte teórico conceitual Urkidi e Walter (2011); Martínez-Alier (2007); Acselrad (2004); e Palacio (2002), entre outros, estes nos ajudaram a compreender como os impactos relacionados à construção de barragens hidroelétricas e as atividades mineradoras suscitam a mobilização social e a preocupação em manter os modos de vida. 
De importância fundamental no processo de identificação das tipologias dos conflitos, estão as técnicas geoespaciais - expressas nos mapas temáticos com representações de fenômenos capazes de serem plotados em linguagem gráfica, acessível aos que buscam ver e ler os mapas. Para tanto, a Geografia vem possibilitando operacionalizar os métodos da Ciência Cartográfica e juntamente com as técnicas de sensoriamento remoto permitem montar um quadro dos conflitos e das tensões estabelecidas na bacia hidrográfica com maior clareza frente à Cartografia de conflitos.

A importância de retratar as questões da Cartografia de conflitos para além da questão da escala e sistemas/projeções de coordenadas está associada a uma tendência bastante recente na Ciência Geográfica, que pode ser autoexplicativa, da qual poderíamos apontar como marco teórico a obra de Maceachren e Taylor (1994); Brewer (1994; 1997); Brewer, Hatchard e Harrower (2003), e Archela e Théry (2008), entre outros.

Estas obras se inserem no contexto das inovações tecnológicas, como o advento dos computadores e da internet; levam a pensar sobre a importância de pesquisas capazes de identificar, analisar e especializar as relações entre usuário e mapa no processo de interação, diante das novas dinâmicas no espaço amazônico.

\section{PERCURSO METODOLÓGICO DA PESQUISA}

A área de estudo delimita-se por toda a bacia de drenagem do rio Itacaiúnas, que é um afluente da margem direita do rio Tocantins e a porção final do médio curso da bacia hidrográfica do rio Tocantins, ambos localizados no extremo leste da Amazônia paraense (Figura 1).

O estudo partiu das questões das representações espaciais e da cartografia temática, por meio de análise crítica dos dados coletados pela Comissão Pastoral da Terra, órgão da Conferência Nacional dos Bispos do Brasil (CPT-CNBB), sobre conflitos no Brasil para o ano de 2018. Este levantamento é bastante rico e possibilitou compreender espacialmente como os conflitos ambientais e socioambientais se configuram no espaço da área em estudo para a construção do mapa de célula de conflitos.

O trabalho de campo e no campo possibilitou a elaboração do mapa de densidade dos pontos de pesca, por meio da coleta de pontos de GPS de alguns pesqueiros, sendo possível construir o mapa de calor. Esta representação consistiu em estimar, através do método estocástico de interpolação, a área de influência dos pesqueiros por meio da concentração de números totais de pontos localizáveis, os quais permitiram a espacialização destes pontos. 
Figura 1 - Mapa situacional da bacia hidrográfica dos Rios Itacaiúnas e médio curso do Rio Tocantins

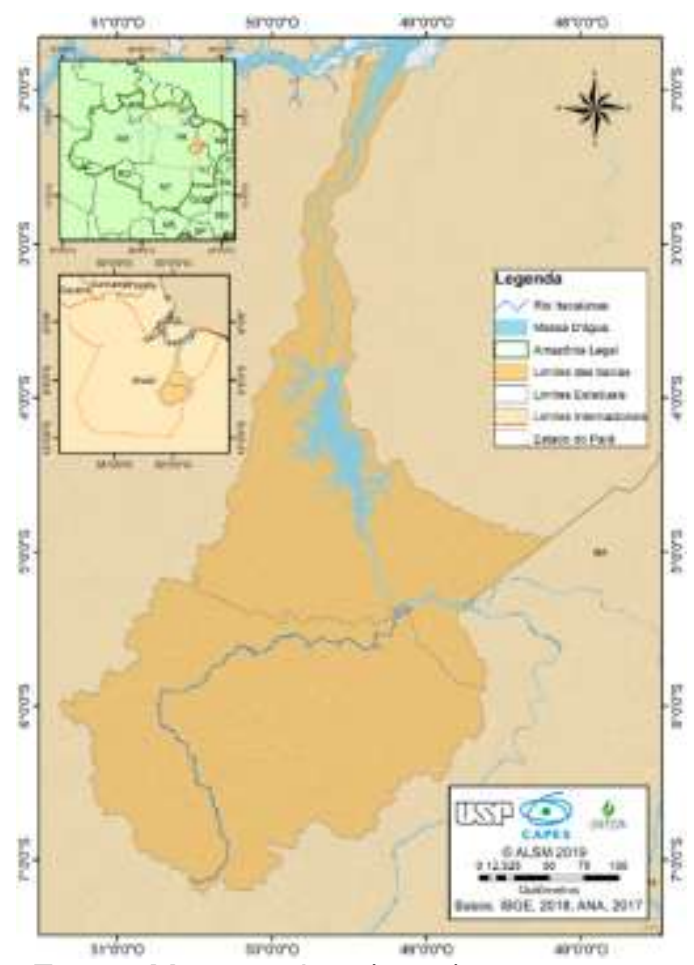

Fonte: Mascarenhas (2020).

A partir do mapa de densidade dos pontos de pesca foi possível gerar um mapa coroplético dos principais conflitos (célula de conflitos) associados ao recurso água. Os mapas coropléticos possibilitaram espacializar os conflitos por recurso água, trazendo a síntese dos registros em municípios que detêm os maiores e/ou menores números de conflitos, sobrepostos ao mapa quantitativo, representados (método geoestatístico) por círculos proporcionais.

A modelagem cartográfica seguiu os pressupostos encontrados em Archela e Théry (2008). Estas autoras afirmam que as metodologias de produção de mapas temáticos devem ser orientadas para facilitar a comunicação e a informação do fenômeno cartografado.

A partir de bases cartográficas (malha municipal do IBGE) foram gerados produtos cartográficos, ambos auxiliados pelos sistemas geoinformativos da plataforma computacional QGIS.3, levando em conta os dados do ano de 2018 que caracterizaram os conflitos agrários e conflitos por uso da terra (áreas geradoras de efluentes de mineração), que tencionam a permanência dos povos indígenas, ribeirinhos, pescadores e assentados da reforma agrária em seus territórios/na área em questão.

A partir da análise das distribuições espaciais dos conflitos e de trabalhos de campo, foi possível construir uma tipologia da dimensão ambiental/socioambiental das lutas comunitárias por justiça ambiental. Ainda para auxiliar na síntese metodológica, autores - 
como Shmueli (2008) em seu artigo intitulado Framing in geographical analysis of environmental conflicts: Theory, methodology and three case studies - trazem a necessidade de framing (construção de um quadro ou esboço) a fim de informar questões complexas sobre os conflitos ambientais e subsidiar estudo para o planejamento.

A opção por quatro grupos de tipologias diferentes (povos indígenas, ribeirinhos, pescadores e assentados da reforma agrária) se deu em função destes serem os primeiros afetados por obras de grande escala como hidrovias, hidrelétricas e estradas; e de ter nesses grupos a permanência de elementos culturais tradicionais/originários. Neles existe uma plêiade de agentes sociais que compartilham de forma comum os recursos naturais na área estudada, tornando-se (assim) palco de disputas e interesses divergentes.

\section{RESULTADOS E DISCUSSÕES: UMA ANÁLISE E SÍNTESE DOS CONFLITOS E TENSÕES DOS RECURSOS TERRA/ÁGUA}

Aponta-se para a importância da construção de um quadro sistematizador para informar questões complexas sobre os conflitos ambientais, tendo-o então como primeira aproximação para identificar as tipologias do capital social dentro da bacia hidrográfica em tela (Quadro 1).

Os projetos de desenvolvimento regional não têm se preocupado com os possíveis conflitos de territorialidades que porventura possam se agravar, porque se utilizam do processo de judicialização para impor os interesses do monopólio das grandes empresas e do agronegócio. Como exemplo, o caso da Usina Hidrelétrica (UHE) de Belo Monte - Pará, pois a formação do painel de especialistas afirmou que o empreendimento do jeito que estava sendo proposto não seria viável (MAGALHÃES; HERNANDEZ, 2009) e mesmo assim o empreendimento foi caracterizado de interesse nacional.

O presente levantamento corrobora com os resultados encontrados por Girardi (2019), nos quais é possível perceber a persistência de conflitos por recursos terra-água em detrimento do interesse nacional. Faz-se importante realizar distinção entre movimentos com caráter eminentemente ambiental (movimento ambientalista stricto sensu) dos movimentos socioambientais como bem nos adverte Sabatini (1997). Ao primeiro, as questões dos conflitos entre empreendimentos e populações locais que têm toda a sua dinâmica socioeconômica impactada; já os conflitos socioambientais se relacionam com direito ao controle e acesso aos recursos. Aqui cabe ter acesso aos recursos naturais terraágua para que os povos indígenas, ribeirinhos, pescadores e assentados da reforma agrária exerçam suas atividades. 
Quadro 1 - Tipologia do capital social disposto nas regiões hidrográficas do Itacaiúnas e Tocantins

\begin{tabular}{|c|c|c|c|c|}
\hline $\begin{array}{l}\text { TIPOLOGIA } \\
\text { SOCIAL }\end{array}$ & $\begin{array}{l}\text { CARACTERISTICAS } \\
\text { SOCIAIS }\end{array}$ & $\begin{array}{l}\text { CENARIOS } \\
\text { AMBIENTAIS }\end{array}$ & $\begin{array}{l}\text { CENARIOS } \\
\text { SOCIOAMBIENTAIS }\end{array}$ & REINVIDICAÇŌES \\
\hline 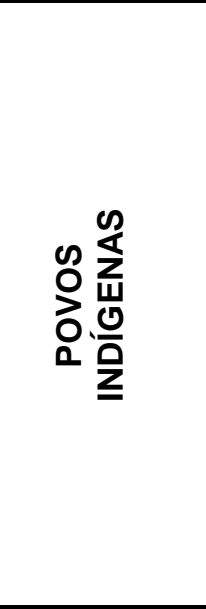 & $\begin{array}{l}\text { - População originária } \\
\text { que detém o } \\
\text { conhecimento milenar } \\
\text { da pesca e da } \\
\text { dinâmica da natureza. } \\
\text { - Atualmente vivem } \\
\text { confinados em } \\
\text { territórios especiais } \\
\text { protegidos (terras } \\
\text { indígenas). }\end{array}$ & $\begin{array}{l}\text { - Poluição } \\
\text { (agrotóxicos ou } \\
\text { rejeitos da } \\
\text { mineração. } \\
\text { - Fragmentação } \\
\text { da floresta. } \\
\text { - Perda da } \\
\text { biodiversidade. } \\
\text { - Inundações de } \\
\text { terras por } \\
\text { barragens. } \\
\text { - Linhas de } \\
\text { transmissão de } \\
\text { energias } \\
\text { cortando as TI. }\end{array}$ & $\begin{array}{l}\text { - Supressão de suas } \\
\text { terras agricultáveis } \\
\text { por conta de formação } \\
\text { de lago de barragem. } \\
\text { - Processos } \\
\text { compensatórios } \\
\text { morosos que não se } \\
\text { efetivam ou têm baixa } \\
\text { efetividade pós- } \\
\text { implementação dos } \\
\text { projetos. }\end{array}$ & $\begin{array}{l}\text { - Fortalecimento das } \\
\text { questões culturais e } \\
\text { respeito às suas } \\
\text { cosmogenias. } \\
\text { - Políticas efetivas } \\
\text { de compensação } \\
\text { advindas dos } \\
\text { projetos de } \\
\text { desenvolvimento } \\
\text { regional que afetam } \\
\text { diretamente duas } \\
\text { populações. }\end{array}$ \\
\hline 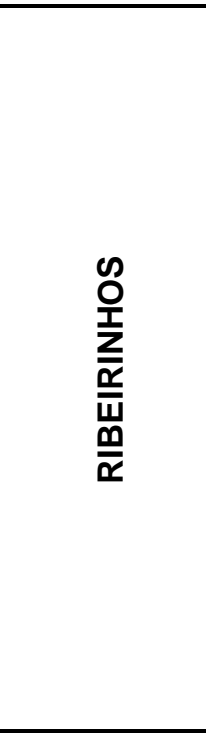 & $\begin{array}{l}\text { - Seu raio de } \\
\text { localização pode } \\
\text { variar entre } 15 \\
\text { quilômetros e as } \\
\text { áreas de várzeas da } \\
\text { calha dos rios. } \\
\text { - Seu modo de vida } \\
\text { tem uma relação } \\
\text { estreita com o rio. } \\
\text { - A pesca é praticada, } \\
\text { mas tem um apego às } \\
\text { atividades agrícolas } \\
\text { como criação de } \\
\text { pequenos animais. } \\
\text { - Às vezes } \\
\text { confundidos com os } \\
\text { pescadores } \\
\text { tradicionais. }\end{array}$ & $\begin{array}{l}\text { - Poluição por } \\
\text { derramamento } \\
\text { de óleo das } \\
\text { embarcações. } \\
\text { - Perda da mata } \\
\text { ciliar, } \\
\text { modificando os } \\
\text { fluxos hídricos } \\
\text { do rio. } \\
\text { - Poluição por } \\
\text { efluentes } \\
\text { urbanos. } \\
\end{array}$ & $\begin{array}{l}\text { - Serão impedidos de } \\
\text { transitar nas áreas } \\
\text { destinadas à hidrovia. } \\
\text { - Poluição do ar e } \\
\text { sonora das barcaças } \\
\text { que transportam } \\
\text { produtos advindos do } \\
\text { agronegócio e seus } \\
\text { insumos. } \\
\text { - Deslocamento } \\
\text { compulsório do seu } \\
\text { lugar de moradia. } \\
\text { - Perda do espaço de } \\
\text { produção agrícola. }\end{array}$ & $\begin{array}{l}\text { - Como utilizam o rio } \\
\text { como via de } \\
\text { transporte, } \\
\text { recreação, } \\
\text { dessedentação de } \\
\text { animais. } \\
\text { - Intentam para seu } \\
\text { direito de ir e vir, } \\
\text { direito ao lazer com } \\
\text { segurança. }\end{array}$ \\
\hline 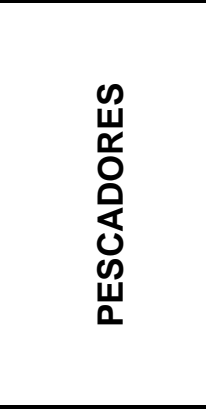 & $\begin{array}{l}\text { - Vivem } \\
\text { majoritariamente do } \\
\text { extrativismo animal e } \\
\text { eventualmente } \\
\text { desenvolvem } \\
\text { atividades de } \\
\text { agricultura de } \\
\text { subsistência. }\end{array}$ & $\begin{array}{l}\text { - Derrocamento } \\
\text { do Pedral de } \\
\text { Lourenço. } \\
\text { - Externalidades } \\
\text { negativas à flora, } \\
\text { à fauna e à vida } \\
\text { aquática. }\end{array}$ & $\begin{array}{l}\text { - Perda da identidade } \\
\text { cultural e de seus } \\
\text { pesqueiros. } \\
\text { - Perda do } \\
\text { conhecimento da } \\
\text { ecologia dos peixes. }\end{array}$ & $\begin{array}{l}\text { - A preservação dos } \\
\text { pontos de pesca. } \\
\text { - Políticas de } \\
\text { ordenamento da } \\
\text { pesca para conter a } \\
\text { sobrepesca nas } \\
\text { bacias hidrográficas. } \\
\text { - Preços justos em } \\
\text { um viés de } \\
\text { economia solidária. }\end{array}$ \\
\hline 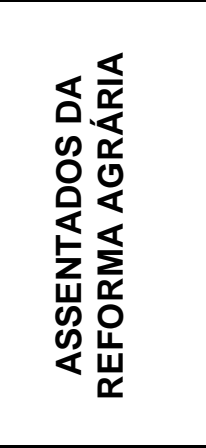 & $\begin{array}{l}\text { - Agricultores que } \\
\text { exercem atividades } \\
\text { agrícolas. } \\
\text { - Ensino nas escolas } \\
\text { do campo. } \\
\text { - Vivenciam o espaço } \\
\text { agrário/agrícola em } \\
\text { áreas de } \\
\text { assentamentos. }\end{array}$ & $\begin{array}{l}\text { - Desmatamento. } \\
\text { - Avanço da } \\
\text { pecuária. } \\
\text { - Plantio de } \\
\text { novas espécies } \\
\text { de capim que } \\
\text { demandam } \\
\text { maior volume de } \\
\text { água. }\end{array}$ & $\begin{array}{l}\text { - Novos } \\
\text { deslocamentos em } \\
\text { terras distantes das } \\
\text { suas terras atuais. } \\
\text { - Políticas } \\
\text { socioeconômicas que } \\
\text { garantam sua } \\
\text { reprodução social. }\end{array}$ & $\begin{array}{l}\text { - Direito ao seu } \\
\text { lugar. } \\
\text { - Esse } \\
\text { pertencimento } \\
\text { advém de eventos } \\
\text { históricos de } \\
\text { apropriação do } \\
\text { território com forte } \\
\text { apego às } \\
\text { características de } \\
\text { topofilia. }\end{array}$ \\
\hline
\end{tabular}

Fonte: adaptado de Mascarenhas (2020). 
Os povos indígenas sempre foram os grupos que mais experimentam impactos advindos de políticas energéticas, minero-metalúrgicas e agropecuárias induzidas pelo governo federal. Os impactos afetam de forma direta seus modos de vida e sua cultura, gerando conflitos socioambientais historicamente repetidos. Entre estes impactos estão a invasão de suas terras para a prática de caça ilegal, desmatamento para instalação de linhas de transmissão de alta e média tensão, fragmentação da paisagem, impedimento de conexão entre fluxos gênicos e impedimento do uso do rio como via de transporte pela construção das barragens.

Estes impactos corroboram com os resultados encontrados por Almeida e Vidal (2019) frente às mudanças impostas à Terra Indígena ( $\mathrm{TI}$ ) Mãe Maria, localizada na bacia hidrográfica do rio Tocantins, onde vive o povo Gavião. Para as questões indígenas e dos conflitos nos cenários socioambientais do quadro 1, se apresentam com as mesmas características encontradas por Mello-Théry (2011) para as terras públicas, e é possível fazer um paralelo com os resultados de Coelho, Cunha e Monteiro (2009) para as unidades de conservação, das quais as pesquisas trazem à tona as implicações das ações do Estado sobre os recursos naturais - a institucionalidade produz contradições e põem em rota de colisão distintos interesses.

De costumes nômades, os povos indígenas se deslocavam dentro da bacia do rio Tocantins, porém, com a construção da Usina Hidrelétrica (UHE) de Tucuruí e consequentemente a formação do lago, os índios foram forçados a se deslocarem e viverem em um espaço territorialmente delimitado. Fazem parte desta realidade um grupo expressivo de etnias como os Gaviões (Terra Indígena Mãe Maria - município de Bom Jesus), Asurinís (Terra Indígena Trocará - município de Tucuruí), Guaranis (ainda buscando reconhecimento de suas Terras - município de Jacundá).

Os modos de vida destas populações foram drasticamente alterados, já que passaram a depender de políticas institucionais para as questões mais gerais, que vão desde pagamento de royalties da mineração até políticas educacionais específicas para escolas indígenas.

Os povos ribeirinhos, habitantes tradicionais das margens dos rios, têm sua cultura e identidade intimamente ligada ao recurso terra-água de forma híbrida, na qual sua subsistência depende tanto da agricultura quanto da pesca artesanal. As populações ribeirinhas na Amazônia vivem a dinâmica das cheias, num ciclo de permanência entre as enchentes e vazantes, estando seu modo de vida secular ligado ao regime de cheias e vazantes dos rios. 
Quando as chuvas enchem os rios, eles inundam lagos e drenam os igarapés, marcando o período das cheias que, por sua vez, regulam a vida dos ribeirinhos. Quando começam as cheias frequentes na bacia do rio Tocantins, torna-se difícil fazer roça, e mesmo a pesca e a caça modificam-se por conta da dinâmica das águas - este período dificulta a vida social. Em períodos de cheias estes povos se dedicam à agricultura de vazante.

Os pescadores têm sua atividade econômica desenvolvida exclusivamente no extrativismo animal, por isso defendem que empreendimento como hidrovia afeta diretamente toda a ecologia das águas, alterando o comportamento da ictiofauna e dos fluxos hídricos. Esta tensão está em voga, já que as colônias de pescadores dos municípios de São João do Araguaia, São Domingos do Araguaia, Marabá, Itupiranga, Nova Ipixuna e Jacundá têm se mobilizado a fim de defender seus territórios de pesca. Esta população será transfigurada em empreendedores para desenvolver a criação de peixe em tanques redes.

Destaca-se um exemplo dessas áreas de tensão no médio curso do rio Tocantins entre Marabá e Itupiranga (Figura 2), onde a pesca artesanal é uma das atividades que poderá gerar conflitos intensos nos próximos anos, se houver a efetivação do projeto de hidrovia - assim conflitos advindos das formas de usar o rio serão cada vez maiores. As hidrovias interferem diretamente nos pontos de pescas. Sendo a pesca uma atividade responsável em garantir a segurança alimentar de grande parte das comunidades às margens dos rios. Há uma simbiose entre ecologia dos peixes e ecologia da pesca. Hoje se tem indicativos da diminuição de determinadas espécies nos rios da Amazônia por conta da construção de hidrelétricas (JUNK; MELLO, 1990).

$\mathrm{Na}$ Figura 2, os principais pontos de pesca revelam o intenso uso por populações haliêuticas que modelam formas de viver e que dependem exclusivamente dos recursos pesqueiros para a manutenção de gêneros de vida e permanência de sua cultura.

E, por fim, os assentados/as da reforma agrária, agricultores que exercem atividades agrícolas, ensino nas escolas do campo, vivenciam o espaço agrário em áreas de assentamentos; seu modo de vida é essencialmente agrário/agrícola; parte deste grupo também já experimentou deslocamentos compulsivos na construção e formação da hidroelétrica e lago da represa de Tucuruí - Pará.

Com a possibilidade de construção da hidrovia Araguaia - Tocantins e Hidrelétrica de Marabá, esses assentamentos passam por intensa especulação imobiliária. Para as populações fica o medo de novas remoções. A venda ilegal de terras está associada ao temor dos assentados de perderem terras agricultáveis e/ou não serem indenizados. 
Figura 2 - Densidade dos pontos de pesca com áreas de potencial conflito

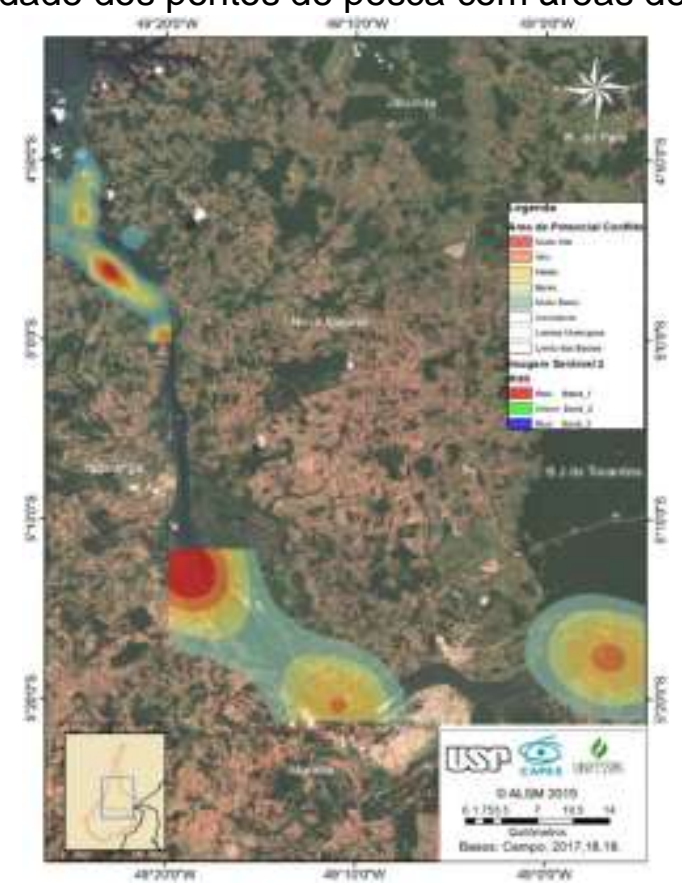

Fonte: Mascarenhas (2020).

Os recursos terra-água são (então) os elementos centrais da reprodução não somente material, mas também simbólica dos povos indígenas, ribeirinhos, pescadores artesanais e comunidade de assentados.

\section{A SÍNTESE DA PESQUISA EM CONFLITOS E TENSÕES DOS RECURSOS TERRA- ÁGUA}

No Brasil as políticas de transporte e logística têm impacto direto sobre a vida das comunidades menos abastadas. Os usos múltiplos e as políticas de transportes intermodais (ferrovia, hidrovia e porto) que vêm sendo pensadas na bacia hidrográfica do TocantinsAraguaia, tomando como exemplo a reestruturação das bacias Itacaiúnas/Tocantins, seguem essa mesma lógica.

Destacamos dois tipos de conflitos nas bacias Itacaiúnas/Tocantins. O primeiro é o conflito ambiental, aquele que está relacionado a externalidades, oriundas das mudanças das formas de uso e ocupação como a produção de lagos artificiais em rios por conta de usinas hidroelétricas (UHE), ou por abertura de estradas de rodagem e instalação de linhas de transmissão de energias. A segunda tipologia encontrada nas bacias é o conflito socioambiental caracterizado pelas disputas pelo acesso/controle dos recursos naturais. As questões dos tensionamentos sociais (ameaças de morte em sua grande maioria) são encontradas em todos os trechos da bacia; somam-se aos já apontados como potenciais 
conflitos que tendem a se agravar pelos próximos anos, caso não sejam empregadas ferramentas de gestão de conflitos nos planos de gestão dos recursos hídricos.

Nos últimos anos os conflitos foram bem registrados pela Comissão Pastoral da Terra e têm revelado onde estão as células de conflitos na Região Amazônica. Os conflitos ambientais e socioambientais formam o que chamamos de células de conflitos (Figura 3), que estruturam a dinâmica social impressa pelos atores envolvidos, ou seja, o Estado e empresas estatais, que impõem um modelo de desenvolvimento desigual, injustamente social e ecologicamente degradante.

Figura 3 - Células de conflitos ambientais envolvendo o sistema terra-água na bacia hidrográfica Itacaiúnas/Tocantins

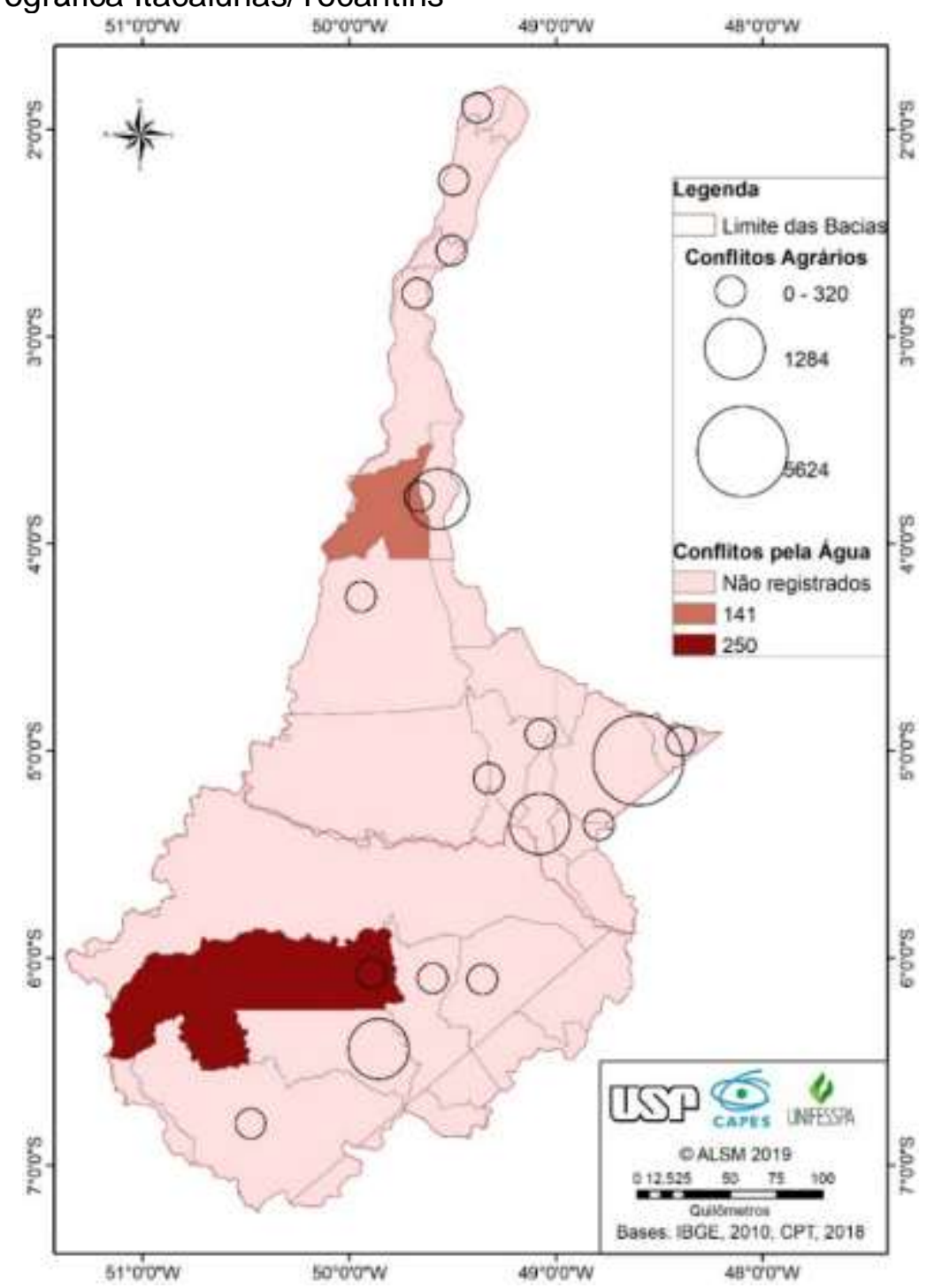

Fonte: Mascarenhas (2020).

Ao observar o mapa pode-se acompanhar a distribuição dos conflitos de jusante a montante das duas regiões hidrográficas (Itacaiúnas e Tocantins), e que há uma concentração dos conflitos na área de influência da Usina Hidrelétrica de Tucuruí. Estes 
conflitos estão bem demarcados e compreendem as áreas no entorno da mineração com disputas de terras em grandes propriedades e na barragem de usina hidroelétrica. Na parte norte da Figura 3 identifica-se a primeira célula de conflitos com índices que se elevam a 1.284 conflitos agrários e 141 conflitos relacionados à água; estes fenômenos de violência se arrastam por anos devido à construção da hidrelétrica e o lago de Tucuruí.

Como agravante tem-se o deslocamento compulsório com inundação de áreas agricultáveis, impedindo a circulação de transporte, associada à barragem UHE de Tucuruí. A modificação da ecologia do rio impediu a troca gênica, modificou os fluxos e inseriu outras dinâmicas que interferiram também em modificações da piracema (FEARNSIDE, 2001). Os mais afetados são os índios da Trocará-Assurinis que não tiveram suas condicionantes cumpridas pelos empreendimentos hidroelétricos da UHE de Tucuruí e pela construção da Rodovia-BR-422/Transcametá. Esses empreendimentos têm direcionado premissas importantes que guiam as questões dos conflitos ambientais e socioambientais, pontuados por lutas para manter a qualidade nos mananciais e acesso aos recursos hídricos (PORTOGONÇALVES, 2011; ZIBECHI, 2006, 2016).

No extremo leste da área encontra-se a segunda célula de conflitos (Figura 3), localizada entre os municípios de Marabá e Bom Jesus do Tocantins, tendo registrado conflitos nas formas de uso entre as atividades da agricultura familiar e as grandes propriedades agropecuaristas, envolvendo mais de 5.600 famílias - esses conflitos envolvem ameaças e expulsões por aqueles que reivindicam serem os donos da terra (CENTRO DE DOCUMENTAÇÃO DOM TOMÁS BALDUÍNO, 2018).

Ainda sobre a Figura 3 , tem-se a terceira célula de conflitos, que se pontua nos municípios de Parauapebas e Canaã dos Carajás, estando sobre a área de influência de projetos de mineração, envolvendo conflitos por sobreposição de terras indígenas e áreas de mineração, com foco na poluição hídrica advinda das barragens de rejeito de minério.

$\mathrm{Na}$ figura 3 é possível identificar as células de conflitos mais intensos, nas microrregiões de Parauapebas (mineração e terras indígenas), na microrregião de Marabá (pecuária e grilagem de terra) e na microrregião de Tucuruí (terras indígenas afetadas pela barragem e formação do lago de Tucuruí), configurando-se como espaços de intensos conflitos e tensões por recursos terra-água.

O cenário de implementação de políticas públicas na Bacia Itacaiúnas/Tocantins tende a exacerbação de conflitos terra-água, que precisam ser equacionados dentro dos planos e ações de políticas públicas - não há mais espaços para tratar dessas tipologias sociais como contingências nos territórios.

O conjunto de recursos terra-água é base do desenvolvimento social. A água age como fator ecológico no desenvolvimento ou no fracasso das civilizações. Um dos 
elementos naturais que mais limita a existência humana, sem dúvida, é a escassez de água. Na história das civilizações temos vastos indícios que o nascimento das cidades ocorre junto às bacias de drenagens. Esta estratégia de sobrevivência está intrinsecamente relacionada à disponibilidade de água e de terras agricultáveis.

Os conflitos e tensões terra-água são lutas pela sobrevivência dentro dos sistemas sociais e dos sistemas socioeconômicos, imbricados no espaço geográfico e que delineiam estruturas territoriais complexas e articuladas entre si - sua base está assentada nos recursos naturais que permitem a existência de um rico capital social, que guarda elementos de diversidade cultural em meio à geodiversidade e à biodiversidade na Amazônia.

As políticas públicas têm suscitado muitas disputas territoriais pelo acesso aos recursos terra, na perspectiva da oportunidade de solo para a produção da agricultura familiar e para a permanência da diversidade cultural dos povos que habitam a bacia hidrográfica e que precisam ser levados em consideração na elaboração de planos e ações de desenvolvimento regional.

Esta conjuntura territorial cercada de aspectos ideológicos e culturais, vista pelas políticas ditas de desenvolvimento, realizadas por agentes do Estado - os quais são responsáveis em construir infraestruturas para dar suporte ao desenvolvimento -, deixa de dialogar com as populações ribeirinhas, com os pescadores, com os indígenas etc. Para qualificar seus estudos de impactos ambientais, as audiências públicas com o objetivo de qualificadora dos elementos de planejamento se transformam em um ambiente de plataforma política dos agentes locais sem alcance esperado para ambas as partes.

Os conflitos de interesses e a preocupação em resguardar modos de vida e desenvolvimento dos projetos de larga escala têm destoado em suas agendas (conflitos de interesses e diversidade de formas de uso). O que temos visto é que os empreendimentos são pensados longe das realidades locais e com forte viés autoritário, transformando populações inteiras em contingências a serem suprimidas pelos agentes públicos, usando como discurso a baixa densidade populacional e os ganhos para a maioria da população do país.

À luz deste contexto é que políticas mais recentes apresentam uma preocupação com o uso racional dos recursos hídricos, mas, na contramão disso, as políticas de integração e infraestruturas dos anos 2000 ainda levam muito pouco em consideração as acepções de sustentabilidade ecológica e a concepção de desenvolvimento regional local. Neste contexto, os usos não consultivos, entrepondo-se sobre usos consultivos, geram demandas por justiça ambiental, exigindo cada vez mais o fortalecimento de uma governança ambiental das pequenas comunidades. 


\section{CONSIDERAÇÕES FINAIS}

Diferenciar conflitos ambientais de conflitos socioambientais, de um ponto de vista geográfico, é refundar as questões entre território, espaço e recursos naturais. Quatro tipologias sociais (povos indígenas, ribeirinhos, pescadores e assentados da reforma agrária) foram elencadas para guiar as questões de conflitos por terra-água na Bacia Hidrográfica do Rio Itacaiúnas e porção do médio curso do rio Tocantins. Dois focos se destacam frente às reivindicações dos povos - o acesso à água e a manutenção da qualidade dos recursos.

Dois tipos de conflitos foram destacados, conflito ambiental (relacionado às externalidades, oriundas das mudanças das formas de uso e ocupação, como a extração de minérios, produção de lagos artificiais e derrocada de pedrais) e conflito socioambiental (caracterizado pelas disputas ao acesso/controle dos recursos naturais).

O mapa de conflitos revelou vetores de explosões de territorialidades, explosões essas pontuadas nas células de conflitos, moldadas pela dinâmica social impressa por diversos atores envolvidos, na qual prevalecem em sua maioria um modelo de desenvolvimento desigual, injusto socialmente e ecologicamente degradante. A representação espacial por meio dos mapas temáticos permitiu localizar e descrever dinâmicas territoriais bastante expressivas. As agendas governamentais devem procurar na governança ambiental uma nova ordem política que busque o desenvolvimento com menos conflitos e tensões, pois os recursos terra-água são essenciais ao desenvolvimento dos povos e riqueza dos Estados.

\section{REFERÊNCIAS}

ACSELRAD, Henri. Justiça ambiental e construção social do Risco. Desenvolvimento e meio ambiente, Curitiba, n. 5, p. 49-60, 2002.

ACSELRAD, Henri. Conflitos ambientais no Brasil. Rio de Janeiro: Relume Dumará, 2004. ALMEIDA, Elson Pereira de; VIDAL, Maria Rita. O uso de elementos de etnomapeamento no ensino de geografia em terras indígenas. Revista NERA, Presidente Prudente, v. 23, n. 54, p. 259-283, 2019.

ARCHELA, Rosely Sampaio; THÉRY, Hervé. Orientação metodológica para construção e leitura de mapas temáticos. Revue Confins, [S. I.], n. 3, p. 1-21, 2008. Disponível em: http://journals.openedition.org/confins/3483. Acesso em: 10 jan. 2020.

BREWER, Cynthia Ann. Color use guidelines for mapping and visualization. In: MACEACHREN, Alan; TAYLOR, Fraser. Visualization in modern cartography. Londres: Pergamon, 1994. v. 2, p. 123-147.

BREWER, Cynthia Ann. Evaluation of a model for predicting simultaneous contrast on color maps. The Professional Geographer, London, v. 49, n. 3, p. 280-294, 1997.

BREWER, Cynthia Ann; HATCHARD, Geoffrey; HARROWER, Mark. ColorBrewer in print: a 
catalog of color schemes for maps. Cartography and Geographic Information Science, [S. I.], v. 30, n. 1, p. 5-32, 2003.

BRUNET, Roger. Le déchiffrement du Monde: théorie et pratique de la Géographie. Paris: Editions Berlin, 2001.

\section{CENTRO DE DOCUMENTAÇÃO DOM TOMÁS BALDUÍNO. Conflitos no campo Brasil} 2018. Goiânia: CPT, 2018.

COELHO, Maria Célia Nunes; CUNHA, Luis Henrique; MONTEIRO, Maurílio de Abreu. Unidades de conservação: populações, recursos e territórios, uma abordagem da geografia e da ecologia política. In: GUERRA, José Teixeira; COELHO, Maria Célia Nunes (org.). Unidades de conservação: abordagens e características geográficas. Rio de Janeiro: Bertrand Brasil, 2009. p. 67-111.

FEARNSIDE, Philip Martin. Environmental impacts of Brazil's Tucuruí Dam: unlearned lessons for hydroelectric development in Amazonia. Journal of Environmental Management, London, v. 3, n. 27, p. 377-396, 2001.

GIRARDI, Eduardo Paulon. Questão agrária, conflitos e violências no campo brasileiro. Revista NERA, Presidente Prudente, v. 22, n. 50, p. 116-134, 2019.

JUNK, Wolfgang Johannes; MELLO, José Alberto Sampaio Nunes de. Impactos ecológicos das represas hidrelétricas na bacia amazônica brasileira. Estudos Avançados, São Paulo, v. 4, n. 8, p.126-143, 1990.

LEROY, Jean-Pierre. Justiça ambiental. 2011. Disponível em: http://conflitosambientaismg.Icc.ufmg.br/wp-content/uploads/2014/04/TAMC-LEROY_JeanPierre_-_Justi\%C3\%A7a_Ambiental.pdf. Acesso em: 10 jan. 2020.

MACEACHREN, Alan; TAYLOR, Fraser. Visualization in modern cartography. Londres: Pergamon, 1994. v. 2.

MAGALHÃES, Sônia Maria Simões Barbosa; HERNANDEZ, Francisco Del Moral (org.).

Painel de especialistas: análise crítica do estudo de impacto ambiental do aproveitamento hidrelétrico de Belo Monte. Belém: INPA, 2009. Disponível em:

http://philip.inpa.gov.br/publ_livres/Dossie/BM/Outros/Belo\%20Monte\%20painel\%20especiali stas.pdf. Acesso em: 20 jan. 2020.

MARTINEZ-ALIER, Juan. Ecologismo dos pobres. São Paulo: Contexto, 2007.

MASCARENHAS, Abraão Levi Santos. Mapas temáticos e modelização gráfica para avaliação das estruturas territoriais em bacias hidrográficas. 2020. Tese (Doutorado em Geografia Humana) - Universidade de São Paulo, São Paulo, 2020.

MELLO-THÉRY, Neli Aparecida. Território e gestão ambiental na Amazônia: terras públicas e os dilemas do Estado. São Paulo: Annablume: Fapesp, 2011.

PALACIO, Germán. Notas sobre la noción de conflicto ambiental: un nuevo matiz en el análisis histórico? In: PALACIO, Germán; ULLOA, Astrid (ed.). Repensando la naturaleza: encuentros y desencuentros disciplinarios em torno a lo ambiental. Colombia: Universidad Nacional de Colombia, 2002. p. 193-203. Disponível em:

https://repositorio.unal.edu.co/bitstream/handle/unal/57002/958818102X.capitulo9.pdf?seque nce $=13 \&$ isAllowed $=y$. Acesso em: 20 jan. 2020.

PORTO-GONÇALVES, Carlos Walter. Amazônia: encruzilhada civilizatória, tensões territoriais em curso. Obrajes: Instituto para el Desarrollo Rural de Sudamérical, 2018. Disponível em:

https://www.sudamericarural.org/images/impresos/archivos/Amazonia_encruzilhada_civilizat oria.pdf. Acesso em: 20 jan. 2020.

PORTO-GONÇALVES, Carlos Walter. Ou inventamos ou erramos: encruzilhadas da integração regional Sul-Americana. In: VIANA, André Rego; BARROS, Pedro Silva; 
CALIXTRE, André Bojikian (org.). Governança global e integração da América do Sul. Brasília: IPEA, 2011. cap. 4, p. 133-175. Disponível em:

http://repositorio.ipea.gov.br/bitstream/11058/3004/1/Livro_Governan\%c3\%a7a\%20global\%2 0e\%20integra\%c3\%a7\%c3\%a30\%20da\%20Am\%c3\%a9rica\%20do\%20Sul.pdf. Acesso em: 20 jan. 2020.

SABATINI, Francisco. Conflictos ambientales en América Latina: ¿distribución de externalidades o definición de derechos de propiedad? In: SABATINI, Francisco;

SEPÚLVEDA, Claúdia (ed.). Conflictos ambientales: entre la globalización y la sociedad civil. [Santiago]: CIPMA, 1997. cap. 3, p. 49-74. Disponível em:

https://www.fuhem.es/media/cdv/file/biblioteca/Conflictos_socioecologicos/Conflictos _ambientales_entre_globalizacion_sociedad_civil.pdf. Acesso em: 20 jan. 2020.

SHMUELI, Deborah Fae. Framing in geographical analysis of environmental conflicts: theory, methodology and three case studies. Geoforum, Oxford, v. 39, n. 6, p. 2048-2061, 2008.

URKIDI, Leire; WALTER, Mariana. Dimensions of environmental justice in anti-gold mining movements in Latin America. Geoforum, Oxford, v. 42, n. 6, p. 683-695, nov. 2011.

VIANNA, Angela Ramalho. Conflitos ambientais no Brasil: natureza para todos ou somente para alguns? Rio de Janeiro: IBASE, 1997.

ZIBECHI, Raúl. IIRSA: la integración a la medida de los mercados. Ecologia Política, Madri, n. 31, p. 19-25, 2006. Disponível em: https://scholar.google.com.br/scholar?hl=pt-

BR\&as_sdt=0\%2C5\&as_vis=1\&q=ZIBECHI\%2C+Ra\%C3\%BAI.+IIRSA\%3A+la+integraci\%C $3 \% B 3 n+a+l a+$ medida+de+los+mercados.+Programa+de+las+Am\%C3\%A9ricas\&btnG=.

Acesso em: 20 jan. 2020.

ZIBECHI, Raúl. Interconexión sin integración: 15 años de IIRSA. Quito: CDES, 2016. Disponível em: http://cdes.org.ec/web/wp-content/uploads/2016/01/Art\%C3\%ADculoZibechi_Interconexi\%C3\%B3n-sin-integraci\%C3\%B3n.pdf. Acesso em: 1 jun. 2017.

ZHOURI, Andrea; LASCHEFSKI, Klemens. Desenvolvimento e conflitos ambientais. Belo Horizonte: UFMG, 2010.

Recebido: agosto de 2020.

Aceito: janeiro de 2021. 